\title{
A Comparative Study on Ultrasonic Machining of Hard and Brittle Materials
}

Departamento de Engenharia Mecânica Universidade Federal de Pernambuco Cidade Universitária 50740-530 Recife, PE. Brazil pguzzo@ufpe.br shinohara@ufpe.br

\author{
A. A. Raslan \\ Faculdade de Engenharia Mecânica \\ Universidade Federal de Uberlândia \\ Campus Sta. Mônica \\ 38400-902 Uberlândia, MG. Brazil \\ Itm-raslan@ufu.br
}

Precision abrasive processes are commonly employed to machine glasses, single crystals and ceramic materials for various industrial applications. Until now, precision machining of hard and brittle solids are poorly investigated in Brazil from the fundamental and applied point of views. Taking into account the major technological importance of this subject to the production of functional and structural components used in high performance systems, the present study investigated the ultrasonic abrasion of different workpiece materials - alumina, zirconia, quartz, glass, ferrite and LiF - by using a stationary ultrasonic machine. Experiments were conducted using a rectangular shaped cutting toll and SiC particles with mean grain size of $15 \mu \mathrm{m}$. The machined surfaces were characterized by surface profilometry and scanning electron microscopy. In the case of alumina, zirconia and quartz, the rates of material removal decrease with the depth of machining. The rate of material removal remained constant for the others materials. The micrographs showed that brittle microcracking was the primary mechanism involved with material removal. The rates of material removal and the machined surface topographies were discussed as a function of intrinsic stiffness, hardness and fracture toughness of workpiece materials.

Keywords: Ultrasonic machining, fracture, surface topography, ceramics, crystals

\section{Introduction}

Hard solids are invariably stiff, strength and wear resistant. On the other hand, hard solids typically exhibit statistically variable brittle fracture and high sensitivity to machining damage. When loaded with tensile stresses, hard solids pass from elastic to fracture behavior and invariably fail by crack extension. Thus, hard solids are usually brittle, i.e., they have small capacity to convert elastic energy into plastic deformation at room temperature (Dieter, 1981).

Brittle and hard solids can be classified in four groups: minerals, polycrystalline ceramic aggregates (traditional and advanced), single crystals and amorphous glasses. Minerals are frequently used as raw materials in the production of a large range of products such as abrasives, gemstones, metals and alloys, single crystals synthetically produced on a commercial scale, etc. Traditional ceramics and glasses are extensively used to manufacture many products currently used in daily life. Advanced ceramics have been widely adopted as functional as well as structural engineering materials (Chiang et al. 1997). Functional ceramics and single crystals are extensively used in the production of electric, electronic, magnetic and optical components for high performance systems such as transducers, resonators, actuators and sensors (Fraden, 1996). The past two decades have seen a tremendous resurgence in the use of advanced ceramics in structural applications such as roller and sliding bearings, adiabatic diesel engines, cutting tools, etc.

Conventional forming and sintering processes of ceramic powders do not necessarily give the high dimensional accuracy and the good surface quality required for functional and structural components. Similarly, the functional devices built with single crystals frequently show monolithic structures with complexes shapes that cannot be achieved during the process of crystal growth. Thus, precision machining technologies have been developed for the manufacture of cost-effective and quality-assured precision parts produced by brittle and hard solids. Several machining techniques can be mentioned like diamond turning, ion and electron-beam

Presented at COBEF 2003 - II Brazilian Manufacturing Congress, 18-21 May 2003, Uberlândia, MG. Brazil.

Paper accepted October, 2003. Technical Editor: Alisson Rocha Machado machining, laser-beam machining and abrasive machining processes (Snoyes 1986, Nakazawa 1994).

Although Brazil is one of the most important suppliers of raw materials to produce functional and structural components for high performance systems, fundamental and applied research connected with the machining of brittle and hard materials are still incipient. On the other hand, the Brazilian commercial balance is usually troubled by mass importation of optical and electronic devices build with advanced ceramics and single crystals. In addition, it is expected that industries installed in Brazil dealing with automotive, aircraft and agricultural machinery will increase their activities in the coming years. If so, an increasing amount of functional and structural components made by advanced materials will be also expected. Under these circumstances, efforts to investigate the machinability of brittle and hard solids by precision manufacturing processes would contribute to the development of a network of domestic suppliers for advanced materials and devices.

In the present paper, preliminary aspects of ultrasonic machining of brittle and hard solids are investigated. Because ultrasonic machining is not broadly adopted by Brazilian manufacturing industries, the first part of this paper was devoted to recall the principle of operation and the main features of this process. Ultrasonic machining experiments were then carried out to machine alumina, zirconia, quartz, soda-lime glass, ferrite and LiF. The cutting rates and the machined surface topographies were measured under a fixed operating condition. The results were discussed in relation to workpiece mechanical properties and analytical models of material removal and surface roughness.

\section{A Survey on Stationary Ultrasonic Machining}

Ultrasonic machining offers a solution to the expanding need for machining brittle materials such as single crystals, glasses and polycrystalline ceramics, and for increasing complex operations to provide intricate shapes and workpiece profiles. This machining process is non-thermal, non-chemical, creates no change in the microstructure, chemical or physical properties of the workpiece and offers virtually stress-free machined surfaces (Kramer 1995, Thoe et al. 1998). It is therefore used extensively in manufacturing hard and brittle materials that are difficult to cut by other conventional methods. The actual cutting is performed either by abrasive particles 
suspended in a fluid, or by a rotating diamond-plated tool. These variants are known respectively as stationary ultrasonic machining and rotary ultrasonic machining (RUM).

Stationary (or conventional) ultrasonic machining (USM) accomplishes the removal of material by the abrading action of a grit-loaded slurry, circulating between the workpiece and a tool that is vibrated at small amplitude. The form tool itself does not abrade the workpiece; the vibrating tool excites the abrasive grains in the flushing fluid, causing them to gently and uniformly wear away the material, leaving a precise reverse form of the tool shape. The uniformity of the sonotrode-tool vibration limits the process to forming small shapes typically under $100 \mathrm{~mm}$ in diameter (Thoe et al. 1998 and papers herein).

The USM system includes the sonotrode-toll assembly, the generator, the grit system and the operator controls. A schematic representation of the USM set-up is shown in Fig. 1. The sonotrodetool assembly consists of a transducer, a booster and a sonotrode. The electronic generator powers the transducer, creating impulses that occur at a range of 19.5 to $20.5 \mathrm{kHz}$, and automatically adjusts the output frequency to mach the resonant frequency of the tool, which varies according to the sonotrode shape and material (Thoe et al. 1998 and papers herein). The transducer converts the electrical pulses into vertical stroke. This vertical stroke is transferred to the booster, which may amplify or suppress the stroke amount. The modified stroke is then relayed to the sonotrode-tool assembly. The amplitude along the face of the tool typically falls in a 20 to $50 \mu \mathrm{m}$ range. The vibration amplitude is usually equal to the diameter of the abrasive grit used.

The grit system supplies a slurry of water and abrasive grit, usually silicon or boron carbide, to the cutting area. In addition to providing abrasive particles to the cut, the slurry also cools the sonotrode and removes particles and debris from the cutting area. The overcut produced with USM is a function of the abrasive particle size, as are the surface finish and the material removal rates (Komaraiah et al. 1988, Thoe et al. 1998). The operator controls provide inputs for manual or automatic sequencing of operations. Controls include variable cutting force, ram position, speed control of the ram movement, cycle timing, retract distance and flush timing.

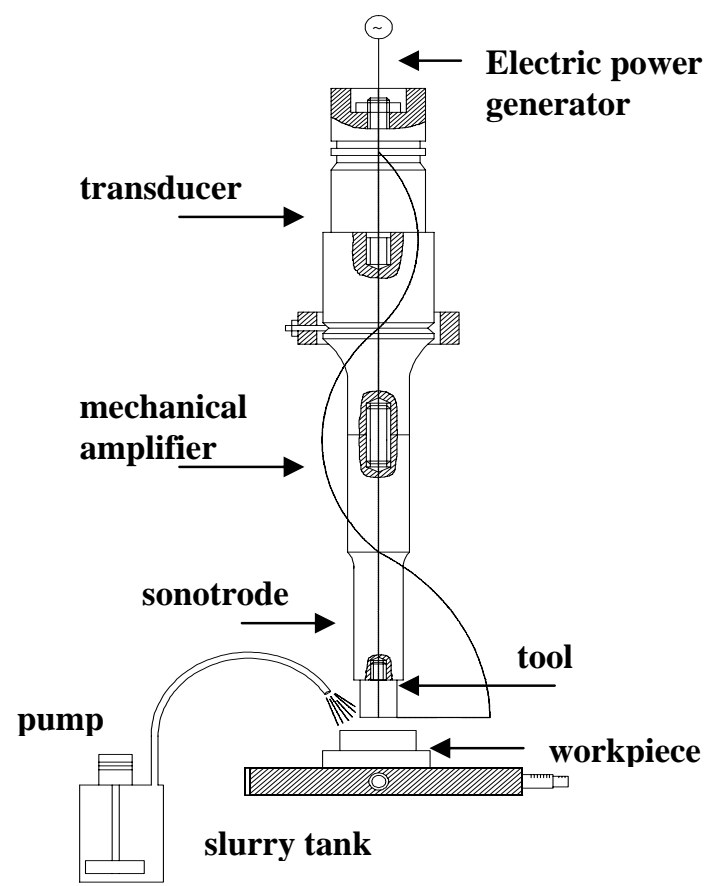

Figure 1. Schematic representation of the USM apparatus.
From the tribological point of view, USM can be classified as a three-body abrasive wear. The material removal is assured by direct hammering and impact action of the abrasive particles against the surface of the workpiece (Shawn, 1956; Kainth et al., 1979). Soundararajan and Radhakrishnan (1986) showed that direct hammering of the abrasive particles on the workpiece by the tool, resulting in material removal and particle crushing, may contributes up to $80 \%$ of the stock removal in brittle solids such as glass. Cavitation effects from the abrasive slurry and chemical action associated with the fluid employed have been reported as minor material removal mechanisms. Material removal rate, surface finish and machining accuracy are influenced by various operational parameters such as amplitude and frequency of ultrasonic oscillations, static load applied on the sonotrode, tool design, hardness and size of abrasive particles (Thoe et al, 1998 and papers herein). The effect of material properties on the rate of material removed was analysed by and Komaraiah and Reddy (1993).

\section{Experimental Procedure}

Small $5 \mathrm{~mm}$ thick blocks of alumina, zirconia, LiF, quartz and soda-lime glass were employed as workpiece materials for the ultrasonic machining tests. Rods of ferrite with $10 \mathrm{~mm}$ in thickness and $23 \mathrm{~mm}$ in diameter were also used. In case of LiF and quartz the machining direction was normal to the planes $\{111\}$ and $\{11 \overline{2} 0\}$, respectively.

Table 1 shows structural and mechanical properties of the workpiece materials. The values of hardness $(H)$ and the fracture toughness $\left(K_{1 c}\right)$ of $\mathrm{LiF}$, quartz and glass samples were determined by the static indentation method using the Vickers indenter (Guzzo et al., 2001). The values of $H$ and $K_{1 c}$ for the other materials correspond to mean values collected from different references.

The USM experiments were carried out in a stationary SonicMill machine with a power output of $1790 \mathrm{~W}$. An electrostrictive PZT transducer converts the electric oscillations into mechanical vibrations in the frequency range of $20 \mathrm{kHz}$. The amplitude of vibration was set at the minimum value and was close to $25 \mu \mathrm{m}$ in the tip of the cutting tool. The static load applied on the sonotrode was kept at $25 \mathrm{~N}$ throughout the experiments. The abrasive slurry was made with silicon carbide (SiC) with mean grain size of $15 \mu \mathrm{m}$ (600 mesh) and water in the ratio 1:2.5 by volume. $E, H$ and $K_{1 c}$ values for standard $\mathrm{SiC}$ varies around $440 \mathrm{GPa}, 25 \mathrm{GPa}$ and 4.5 MPa.m ${ }^{1 / 2}$, respectively. The cutting toll having a solid rectangular cross section with $8.2 \times 1.4 \mathrm{~mm}^{2}$ and $15 \mathrm{~mm}$ in length was manufactured in stainless steel by conventional machining processes.

The material removal rate or the cutting rate $(C R)$ was determined by measuring the time expended to machine a given depth $(p)$ in several stages of machining. The value of $p$ was set between 20 and $200 \mu \mathrm{m}$ depending on the machinability of the workpiece. The roughness profiles of the surfaces achieved by USM were measured with a Rank Taylor Robson profilometer, type Surtronic $3+$, using a cut-off value of $0.8 \mathrm{~mm}$. The center line average $\left(R_{a}\right)$ and the average of the peak-to-valley heights $\left(R_{z}\right)$ were chosen to characterize the machined surface topographies. By using a Carl Zeiss DSM 94A microscope, scanning electron microscopy (SEM) was employed to characterize the micromechanisms related to material removal under ultrasonic abrasion condition.

\section{Results and Discussion}

Figure 2 illustrates the variation of the cutting rate $(C R)$ as a function of the cutting depth $(p)$ for all workpiece materials investigated here. Two different behaviors are noticed. In the case of alumina, zirconia and quartz, $C R$ decreases with $p$ in the first half 
part of the machining process. Afterwards, it remained almost constant. In the case of ferrite, glass and $\mathrm{LiF}$, the $C R$ seemed to be independent of $p$ throughout the machining process. By increasing $p$, the decrease of $C R$ is usually explained by the insufficiency in recycling abrasive particles at the machining interface. The recycling capacity affects the hammering and impact actions of the abrasive particles in the working gap. In addition, the problem with slurry turbulence probably increases with $p$ causing a decrease in the CR.

Table 1. Structural and mechanical properties of workpiece materials.

\begin{tabular}{|c|c|c|c|c|c|c|}
\hline Material & $\begin{array}{c}\text { Chemical } \\
\text { Composition } \\
\end{array}$ & $\begin{array}{c}\text { Crystalline } \\
\text { Structure } \\
\end{array}$ & $\begin{array}{l}\text { Density } \\
\left(\mathrm{g} / \mathrm{cm}^{3}\right) \\
\end{array}$ & $\begin{array}{c}E \\
(\mathrm{GPa}) \\
\end{array}$ & $\begin{array}{c}H \\
(\mathrm{GPa}) \\
\end{array}$ & $\begin{array}{c}K_{I c} \\
\left(\mathrm{MPam}^{1 / 2}\right) \\
\end{array}$ \\
\hline Alumina & $\mathrm{Al}_{2} \mathrm{O}_{3}$ & FCC/polycristalline & 4.0 & $210-380$ & $14-20$ & $3-5$ \\
\hline Ferrite & - & - / polycristalline & - & $\sim 180$ & 6.8 & 1 \\
\hline $\mathrm{LiF}$ & $\mathrm{LiF}$ & FCC/single-crystal & 2.43 & 54.6 & $0.92 \pm 0.03$ & 1.5 \\
\hline Quartz & $\mathrm{SiO}_{2}$ & Trigonal/single-crystal & 2.65 & 78.3 & $15.0 \pm 1.0$ & $0.53 \pm 0.01$ \\
\hline Soda-lime glass & $\mathrm{SiO}_{2}+\mathrm{Na}_{2} \mathrm{O}+\mathrm{CaO}$ & Amorphous & 2.5 & 69 & $5.8 \pm 0.5$ & $0.48 \pm 0.05$ \\
\hline Zirconia & $\mathrm{ZrO}_{2}$ & Tetragonal/polycristalline & 5.8 & $140-210$ & $10-12$ & $8-10$ \\
\hline
\end{tabular}
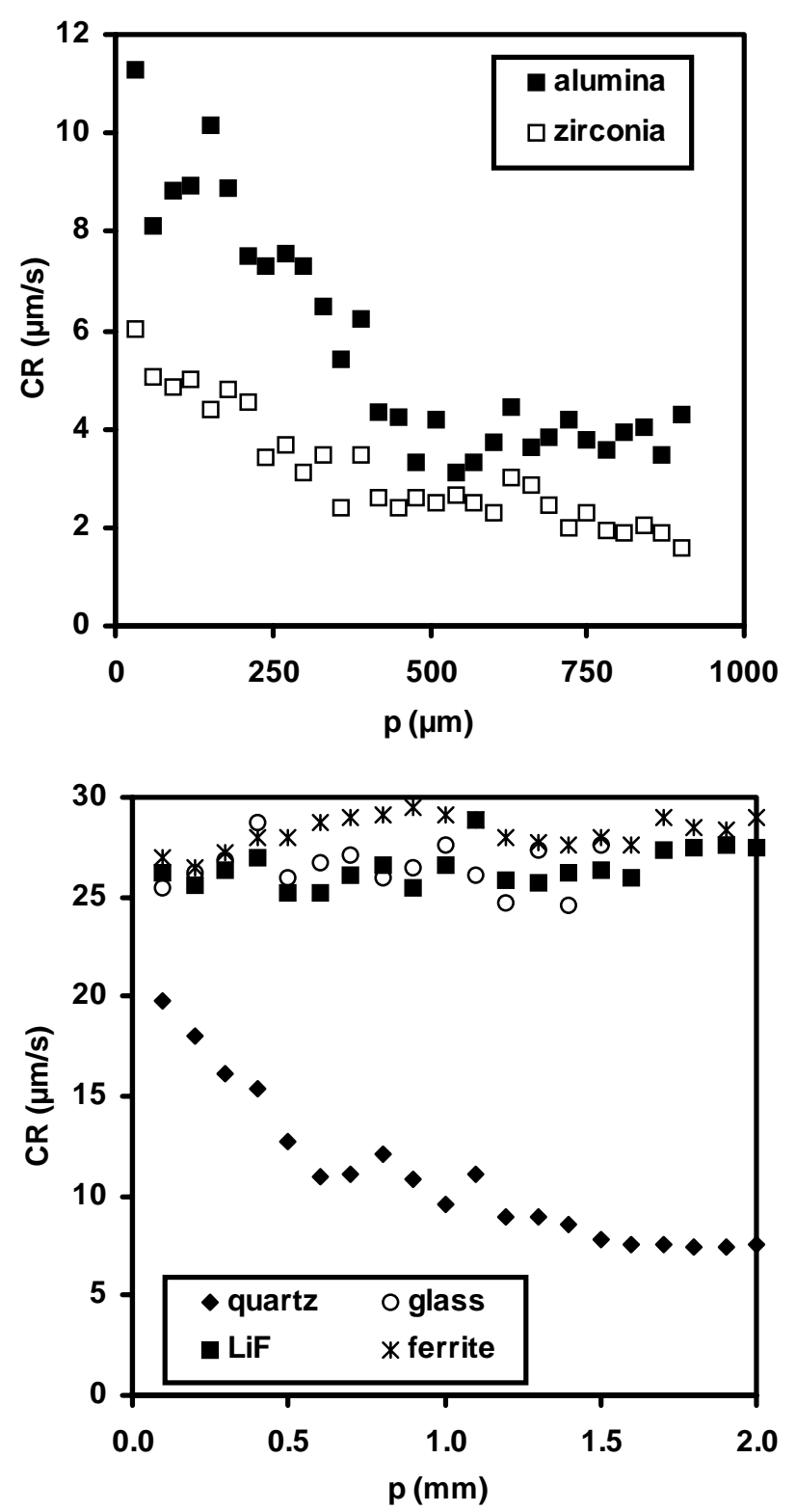

Figure 2. Variation of the cutting rate $(C R)$ as a function of the cutting depth $(p)$.
Because the decrease on $C R$ with $p$ was not observed for all the materials investigated, it is reasonable to suggest that such behavior is much more influenced by the intrinsic properties of the workpiece material than to any operating parameter. Considering the properties listed in Table 1, it is noticed that the main difference between the two groups of materials resides in its hardness. It is observed that the hardness of alumina, zirconia and quartz are in the same order of magnitude than $\mathrm{SiC}$ grits. Above a certain value for workpiece hardness, the abrasive particles loose its cutting power before ending one stage of slurry cycling at the working gap. Such critical hardness for the workpiece material determining the $C R$ vs. $p$ behavior is probably connected with both mechanical properties and shape of abrasive particles.

The fracture toughness should also be considered in the analysis of $C R$ vs. $p$ relationships because both alumina and zirconia are relatively tough compared with the materials studied. It is known that microstructural characteristics of polycrystalline aggregates (grain boundaries, second phase, precipitates) or toughening mechanisms (stress induced phase transformation, crack bridging) may improve the fracture resistance of brittle materials (Sakai and Bradt, 1993). Under USM conditions, the increase in the fracture toughness due to martensitic transformations induced by mechanical stress, as it is usually observed in partial stabilized zirconias (Heuer et al. 1986), is an hypothesis that deserves further investigations. Although less effective, it has been reported that alumina can also shows some mechanisms to contention of fracture by means of the grain boundaries (Swanson et al. 1987). In case of quartz crystal, there is any evidence of microstructural transformations induced by mechanical stress that would increase the fracture toughness. However, it should be pointed out that uniaxial stress applied along suitable directions may induce twinning at stress levels much lower than those required to cause fracture (Guzzo and Boy, 2000).

The mean values of $C R$ are shown in Table 2. For those materials in which $C R$ was independent from $p, C R$ corresponds to the average of all points shown in Fig. 2. For those materials in which $C R$ decreased with $p$, the mean value of $C R$ was determined after reaching the steady-state condition. For alumina and zirconia, $C R$ was determined for the interval $450<p<900 \mu \mathrm{m}$ whereas for quartz the interval considered was $1.0<p<2.0 \mathrm{~mm}$. Table 2 also shows the mean values of $R_{a}$ and $R_{z}$ measured on the surfaces generated by USM. From Table 2, it is observed that material removal rates and the roughness of USM surfaces are dependent on materials characteristics. Figure 3 illustrates typical SEM micrographs of ultrasonically machined surfaces. 
Table 2. Mean values for the cutting rate $(C R)$ and surface roughness parameters.

\begin{tabular}{|l|c|c|c|}
\hline Material & $C R(\mu \mathrm{m} / \mathrm{s})$ & $R_{a}(\mu \mathrm{m})$ & $R_{\mathrm{z}}(\mu \mathrm{m})$ \\
\hline Alumina & $3.8(0.4)$ & $1.5(0.2)$ & $10.9(1.0)$ \\
\hline Zirconia & $2.3(0.4)$ & $1.7(0.4)$ & $10.7(1.9)$ \\
\hline Quartz & $8.4(1.2)$ & $1.5(0.2)$ & $9.6(1.6)$ \\
\hline Soda-lime glass & $26.5(1.1)$ & $2.5(0.4)$ & $14.0(1.8)$ \\
\hline Ferrite & $28.2(0.8)$ & $1.9(0.2)$ & $11.6(0.6)$ \\
\hline LiF & $26.5(0.9)$ & $0.8(0.2)$ & $4.6(1.2)$ \\
\hline
\end{tabular}

(-) standard deviation

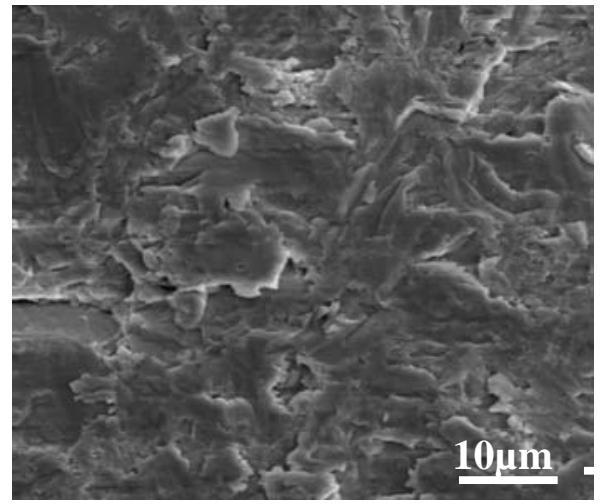

(a) alumina

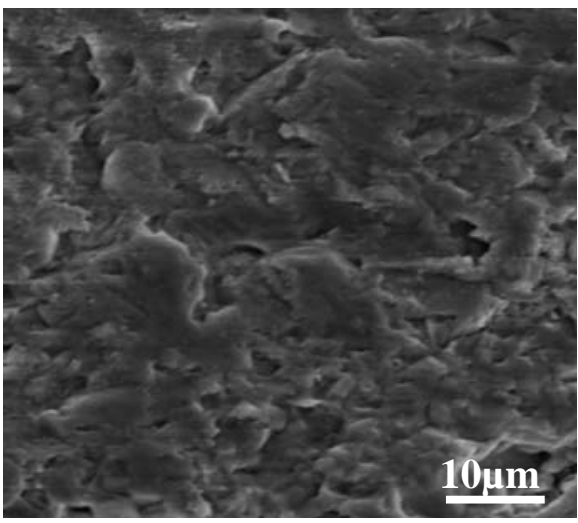

(b) zirconia

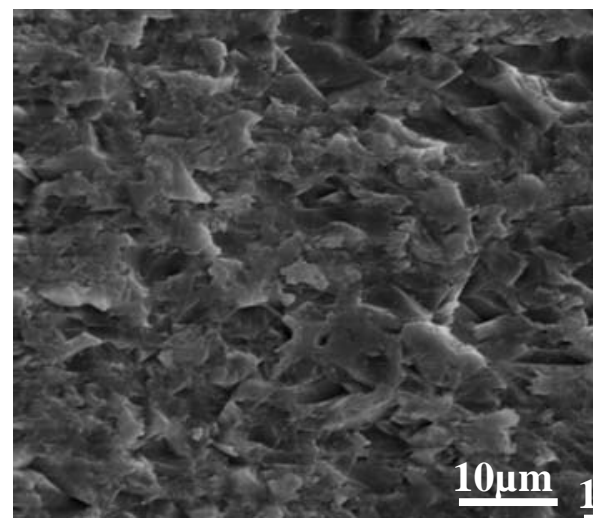

(c) quartz $\{11 \overline{2} 0\}$

Figure 3. SEM micrographs of ultrasonically machined surfaces with SiC grits of $15 \mu \mathrm{m}$.

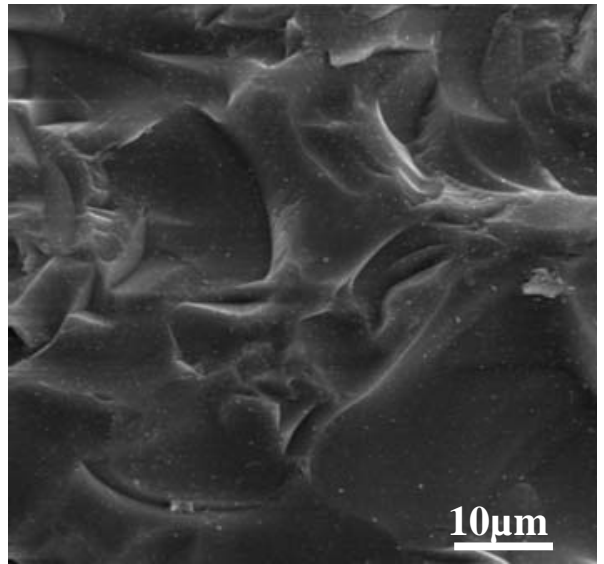

(d) glass

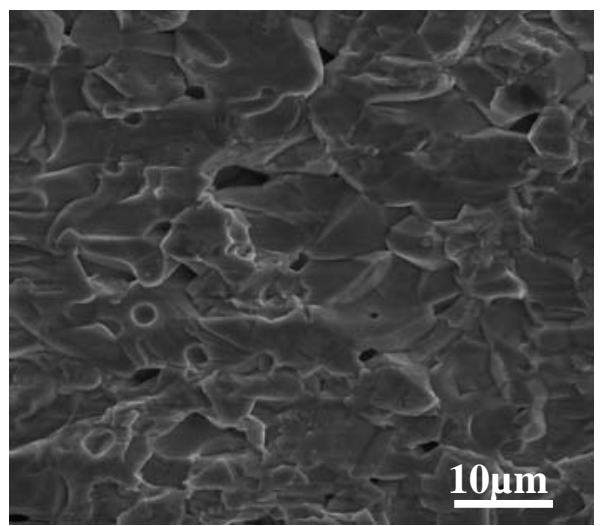

(e) ferrite

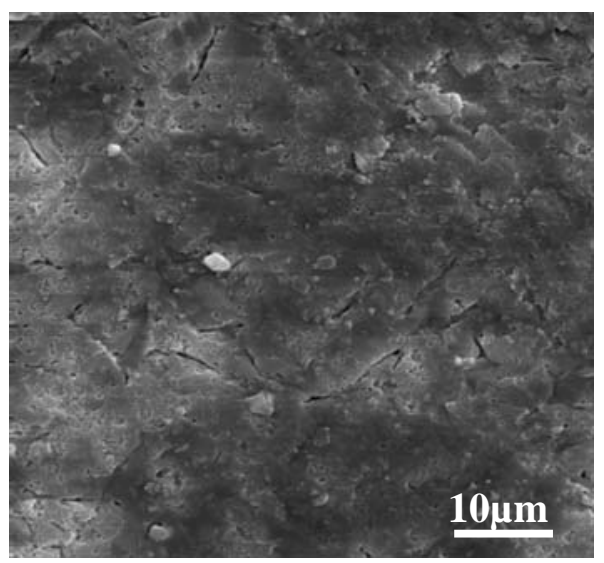

(f) $\operatorname{LiF}\{111\}$

Figure 3. (Continued).

SEM micrographs made clear that brittle microcracking (Zum Gahr, 1987) is the dominant material removal mechanism connected with the ultrasonic abrasion of hard and brittle materials. It is observed that the sizes of the fracture events such as microcracks and microcavities as well as the roughness culaineters $R_{a}$ and $R_{\mathrm{z}}$ are larger for soda-lime glass when compared with the others materials. The mediocre surface finish and the high-grade rate of material removal is because soda-lime glass shows simultaneously the lowest values for hardness and fracture toughness. Although LiF, soda-lime glass and ferrite show similar CR, the machined surface of the former indicates that material removal is controlled by gentle brittle microcracking. The machined surface of $\mathrm{LiF}$ is rather flat containing thin cracks and relatively shallow cavities. The mechanical properties of LiF listed in Table 1 indicate that it is also a brittle 
material. However, it is known that LiF easily cleaves along $\{100\}$ planes (Schultz et al. 1994). Thus, the high-grade rate of material removal in connection with a relatively small surface roughness is explained by the operation of cleavage together with brittle microcracking during the ultrasonic abrasion of LiF.

Quartz crystal and polycrystalline alumina, zirconia and ferrite have similar values for $R_{a}$ and $R_{z}$ but show some differences in machined surfaces from the qualitative point of view. In case of quartz, there is neither cleavage planes nor significant difference on $K_{1 c}$ between low index planes (Schultz et al. 1994, Guzzo et al. 2001). Even though, some preferential directions in fracture opening is observed on its machined surfaces. The intermediate rates of material removal are probably connected with its elevated hardness and low fracture toughness. The absence of cleavage planes does not contribute to improve the quality of the machined surface in quartz workpiece.

When compared to alumina and zirconia the machined surface of ferrite seems to be rather flat and controlled by intergranular fractures. It also shows porosities connected with the forming process. Besides microcracks and microcavities, the surfaces of alumina and zirconia show residual amounts of material that were not completely detached from the surface during the machining process. These observations contribute to conclude that fracture toughness is the main parameter controlling brittle microcracking in polycrystalline aggregates because the hardness of zirconia is smaller than that of alumina and quartz.

Indentation fracture analysis in brittle solids made clear that lateral crack extension could provide a basis for estimating material removal rates for several practical situations (Evans and Wilshaw, 1976). Extending this analysis to stationary USM conditions (Komaraiah and Reddy, 1993), the volume of material (V) that might be removed per unit of time can be expressed as:

$$
V \propto \frac{P^{2}}{K_{1 c}^{3 / 2} H^{1 / 2}} \frac{f}{n}
$$

where $P$ is the static load $[\mathrm{N}], f$ is the frequency of ultrasonic machining $[\mathrm{Hz}]$ and $n$ is the effective number of abrasive particles in the gap between the tool and the workpiece. From Eq. (1) it is observed that the material removal rate is inversely proportional to the product $K_{1 c}{ }^{3 / 2} H^{1 / 2}$. Figure 4 shows the relationship between CR and the product $K_{1 c}{ }^{3 / 2} H^{1 / 2}$ for the materials investigated here.

It is clear that the rate of material removal is not satisfactorily expressed by the relationship of mechanical properties depicted by Eq. 1. If progress is to be made therefore in formulating models for the material removal of brittle and hard materials it must be done it terms of material microstructure such as grain size, grain strength, amount of second phases and its strength, and also in terms of the main operational conditions such as load and abrasive characteristics. Part of this discrepancy may be due to uncorrected values of mechanical properties for alumina, zirconia and ferrite. The density is another property that should be carefully considered in further analytical models.

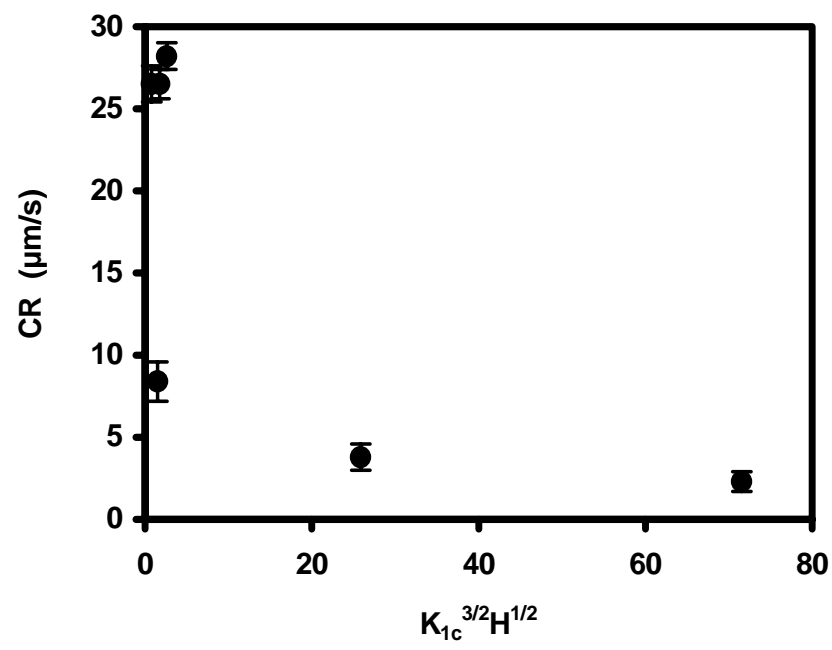

Figure 4. Relationship between the cutting rate $(C R)$ with the mechanical properties of workpiece materials.

Based on the depth of lateral fractures induced by an indenting particle, Buijs and Korpel van Houten (1993) suggested that the roughness of lapped surfaces of glass is associated with the mechanical properties of the workpiece as follows :

$$
R_{z}=\alpha \frac{E^{1 / 2}}{H} F_{i}^{1 / 2}
$$

where $\alpha$ is a constant depending on the abrasive particle shape and $F_{i}$ is the force per particle $(\mathrm{N})$. Even though the material removal mechanims in lapping occurs by multiple indentions and scratches (Chauban et al. 1993), Eq. (2) can be adopted to analyse the surfaces achieved by USM because in both processes brittle microcracking is supposed to be controlled by the interaction of lateral crack vents.

The relationship between $R_{\mathrm{z}}$ and the product $E^{1 / 2} H^{-1}$ is plotted in Fig. 5. The small surface roughness of $\mathrm{LiF}$ can not be explained by the model depicted by Eq (2). This fact confirms that brittle microcracking is not the dominant material removal mechanism operating during the ultrasonic machining of LiF. Although the experimental points tend to follow the model after rejecting $\mathrm{LiF}$, the scattering is still large. Besides the uncertainness related to material properties, brittle microcracking in lapping occurs by multiple indentations and scratches (Chauban el al. 1993) whereas it occurs by hammering and impact action of abrasive grits during the ultrasonic abrasion. Thus, even though material removal occurs by the interaction of lateral crack vents, the surface roughness resultant from USM and lapping processes is not similar. In case of quartz it has been observed that lapping gives smooth surfaces than USM when abrasive grits with same mean grain size are used (Guzzo and De Mello, 2000). 


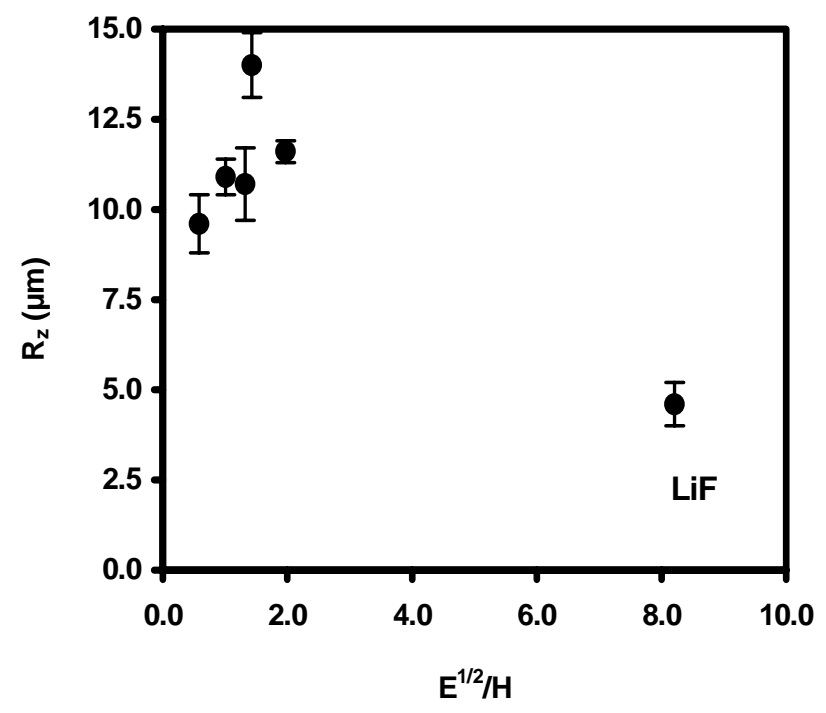

Figure 5. Relationship between the average peak-to-valley roughness $\left(R_{z}\right)$ with the mechanical properties of workpiece materials.

\section{Conclusion}

Preliminary USM experiments carried in different brittle and hard materials revealed the influence of structural and mechanical properties of workpiece materials on the rate of material removal and the topography of machined surfaces. The rate of material removal abruptly decreased with the machining depth for workpiece materials in which hardness is at the same order of magnitude than the hardness of abrasive grits. Under these circumstances, it is believed that abrasive grits lost its cutting power more quickly then the recycling period.

It was observed that brittle microcracking was the dominant mechanism of material removal, except for LiF single crystal. In this case, brittle cleavage is the major mechanism contributing to improve the surface quality. The models used to explain the material removal rate and the surface roughness in relation to material properties did not satisfactorily agreed with the experimental data. Thus, further attempts are required to establish alternative models of machinability of brittle and hard materials under ultrasonic abrasion conditions.

\section{Acknowledgments}

The authors are grateful to Dr. Carlos S. Muranaka from Escola Politecnica of Universidade de São Paulo to supply them with ferrite samples. The measurements of hardness in LiF were carried out by Rafael L. Carvalho. This work was supported by the Instituto Fábrica do Milênio of CNPq. One of the authors (PLG) is a researcher from the Profix Program from CNPq.

\section{References}

Buijs, M. and Korpel-van Houten, K., 1993, “A model for lapping of glass”, J. Mat. Sci., Vol. 28, pp. 3014-3020.

Chauhan, R., Ahn, Y., Chandrasekar, S. and Farris, T.N., 1993, "Role of indentation fracture in free abrasive machining of ceramics", Wear, Vol. 162-164, pp. 246-257.

Chiang, Y.M., Birnie III, D. and Kingery, W.D., 1997, "Physical Ceramics”, The MIT Series in Materials Science and Engineering, Ed. J. Wiley and Sons, Inc., New York, USA, 522p.

Dieter, G.E., 1981, "Metalurgia Mecânica”, Ed. Guanabara Dois, Rio de Janeiro, Brasil, 653p.

Evans, A.G. and Wilshaw, T.R., 1976, "Quasi-static solid particle damage in brittle solids I - Observations analysis and implications", Acta Metallurgica, Vol. 24, pp. 939-956.

Fraden, J., 1996, "Handbook of Modern Sensors", $2^{\text {a }}$ ed., Ed. Springer, New York, USA, 556.

Guzzo, P.L. and Boy, J.J., 2000. "The roles of crystallographic orientation and crystal origin in ferrobielastic twinning of quartz under uniaxial stress”, Eur. Phys. J. AP, Vol. 12, pp. 17-30.

Guzzo, P.L. and De Mello, J.D.B., 2000, "Effect of crystal orientation on lapping and polishing processes of natural quartz", IEEE Trans. On Ultrasonics, Ferroelectrics and Freq. Control, Vol. 47, No. 5, pp. 1217-1227.

Guzzo, P.L., Jacomine, L. and De Mello, J.D.B., 2001, "Evaluation of hardness and fracture toughness in natural quartz crystals by indentation experiments", Proc. of the $16^{\text {th }}$ Brazilian Congress of Mechanical Engineering, Vol. 2, Uberlândia, Brasil, pp.155-161.

Heuer, A.H., Lange, F.F., Swain, M.V. and Evans, A.G., 1986, "Transformation toughening : an overview", J. Am. Ceram. Soc., Vol. 65, No. 5, pp. 1-4.

Kainth, G.S., Nandy, A. and Singh, K., 1979, "On the mechanism of material removal in ultrasonic machining”, Int. J. MTDR, Vol. 19, pp.33-41.

Komaraiah, M., Manan, M.A., Reddy, P.N. and Victor, S., 188, "Investigation of surface roughness and accuracy in ultrasonic machining", Precision Engineering, Vol. 10, No. 2, pp. 59-65.

Komaraiah, M. and Reddy, P.N., 1993, "A study on the influence of workpiece properties in ultrasonic machining”, Int. J. Mach. Tools Manufact., Vol. 33, No. 3, pp. 495-505.

Kramer, D., 1995. “Ultrasonically assisted machining”, Mech. Ind. Mater., Vol. 48, pp. 15-21.

Nakazawa, H., 1994, “Principles of Precision Engineering”, Ed. Oxford Univ. Press, London, UK. 25-53.

Shaw, M.C., 1956, "Ultrasonic grinding”, Annals of CIRP, Vol. 5, pp.

Sakai, M. and Bradt, R.C.,1993, "Fracture toughness testing of brittle materials”, Int. Mat. Rev., Vol. 38, No. 2, pp. 53-78.

Schultz, R.A., Jensen, M.C. and Bradt, R.C., 1994, "Single crystal cleavage of brittle materials”, Int. J. of Fracture, Vol. 65, pp.291-312.

Snoyes, R., 1986, "Non-conventional machining techniques : the state of art”, Advances in Non-Traditional Machining, ASME, pp.1-20.

Soundararajan, V. and Radhakrishnan, V., 1986, "An study on the mechanisms involved in ultrasonic machining”, Int. J. Machine Tool Design and Res., Vol. 26, No. 3, pp. 307-321.

Sreejith, P.S., Ngoi, B.K.A., 2001, "Material removal mechanisms in precision machining of new materials”, Int. J. Mach. Tools Manufact., Vol. 41, pp. 1831-1843.

Swanson, P., Fairbanks, C.J., Lawn, B.R., Mai, Y.W. and Hockey, B.J., 1987, J. Am. Ceram. Soc., Vol. 70, No. 4, pp. 279-285.

Thoe, T.B., Aspinwall, D.K. and Wise, M.L.H., 1998, "Review on ultrasonic machining”, Int. J. Mach. Tools Manufact., Vol. 38, No. 4, pp. 239-255.

Zum Gahr, K.H.,1987, “Microstructure and wear of materials”, Elsevier Sc. Pub., Amsterdam, Netherlands, 554p. 